\title{
TENERLOS EN LA CASA: THE MATERIAL WORLD AND CRAFT OF FAMILY CAREGIVING FOR RELATIVES WITH DEMENTIA ${ }^{1}$
}

Carmen de la Cuesta Benjumea

Professor

Faculty of Nursing

Universidad de Antioquia

Medellin,

Colombia.

Margarete Sandelowski.

Professor

School of Nursing

North Carolina University-Chapel Hill.

USA

\begin{abstract}
Background: The role of the environment in reducing problem behavior in dementia patients, in promoting their well-being, and in facilitating activities of daily living has been increasingly acknowledged. Although family caregivers' expertise is acknowledged in matters relating to patients' environment, and professionals have used them to introduce changes in the home, caregivers' active role in creating and transforming this environment has received less attention. In the study reported here, family caregivers were primary agents and artisans and dementia care appeared as a kind of craft.
\end{abstract}

Aim: The purpose of the study was to identify strategies Colombian family caregivers used in the home to manage the demands of care of relatives in advanced stages of dementia.

Methods: A grounded theory study. Data were collected in Medellín from interviews with 18 primary caregivers of relatives with advanced dementia and 2 health care professionals, and from participant observation in caregivers' support groups and homes. Constant comparison analysis was used after entering data into QSR Nvivo.

\footnotetext{
${ }^{1}$ Este articulo ha sido publicado en Journal of Transcultural Nursing. 16, 218-225, 2005
} 
Findings: Family caregivers built and rebuilt the environment as the disease progressed to accommodate caregiving and preserve family life. The built environment became a place in which care could live. Caregivers accommodated the home to the patient, modified objects in the home, and found new uses for objects to build a physical environment conducive to both caregiving and family life.

Conclusions: Caring for a relative with dementia is not only a practical activity, but also a craft that transforms the material world in which patient and caregiver live. The findings here show the value of a more material and place-sensitive approach to the study of caregiving.

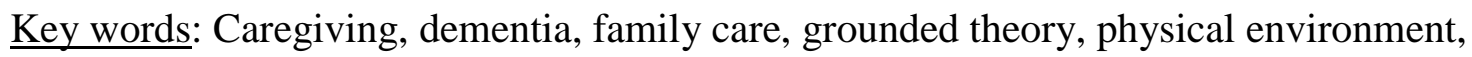
qualitative research.

\section{ACKNOWLEDGMENTS}

This study was funded by a grant from the Research Development Committee of the Universidad de Antioquia, Medellin, Colombia. A major portion of the analysis took place while the first author was a Visiting Professor at the University of North Carolina at Chapel Hill. 


\section{What is already known on this topic}

-The physical environment is conceived as a therapeutic landscape and healing milieu.

-Dementia has been a disease of particular interest to researchers focused on the physical environment of care.

-The physical environment plays a key role in promoting the well-being of dementia patients by facilitating activities of daily living and reducing problem behaviour.

\section{What this study adds}

-Family caregivers are viewed as bricoleurs who are able to see the possibilities of spaces and everyday objects, and to use them in ingenious ways.

-The home environment is viewed as a hybrid place where caregiving and identities are transformed. 


\section{TENERLOS EN LA CASA: THE MATERIAL WORLD AND CRAFT OF FAMILY CAREGIVING FOR RELATIVES WITH DEMENTIA}

\section{INTRODUCTION AND BACKGROUND}

The physical environment for health has been an area of growing interest in recent years. Public health, nursing, urban studies, architecture, and medical geography are among the disciplines concerned with the link between the environment and health. Yet this interest is hardly new. Florence Nightingale (1992/1859) emphasized the importance of the physical environment to the patient's recovery and the role of the nurse as an environmental manager. Her ideas revolutionized hospital design. Late $19^{\text {th }}$ and early $20^{\text {th }}$ century public health initiatives established the relationship between housing conditions and infectious diseases (Krieger \& Higgins 2002). At the dawn of the $21^{\text {st }}$ century, a new body of literature has emerged revitalizing interest in the physical environment as a therapeutic landscape and healing milieu, resulting in such positive outcomes as reduced use of pain medications and earlier discharge from hospitals (Gesler 1992, Stichler 2001).

Dementia has been a disease of particular interest to environmentally-focused researchers (Grant \& Sommers 1998, Morgan \& Stewart 1997 1999). In their review of empirical research on environmental design, Day, Carreon, and Stump (2000) found that, since the early 1980s, numerous guides have been written to enhance the safety, comfort, and well-being of people with dementia in care facilities. This review indicated that four types of studies on design and dementia have been conducted: (a) environmental comparison studies, in which two or more facility types are compared to ascertain impact on residents, staff, and family: for example, special care units and non- specialized units versus skilled nursing facilities, such as respite and day care units; (b) design features studies, in which the effects of specific environmental 
interventions are assessed, such as door modification to prevent unwanted patient exit, interventions to prevent falls, and strategies to enhance patient's orientation; (c) environmental services and policy studies, in which organizational decisions and policies for dementia care environments are examined, such as the impact of relocating patients to new environments: for example, from a day care center to an enhanced facility, and from a psychogeriatric ward to a community nursing home; and, (d) studies on problem behaviors of residents that create difficulties in caregiving: for example, stressful aspects of bathing and exiting behaviour. Of these four categories of studies, investigations of design features and environmental comparisons have been the most prevalent (Day, Carreon, and Stump 2000).

The role of the environment in reducing problem behavior in dementia patients, in promoting their well-being, and in facilitating activities of daily living has been increasingly acknowledged. Most studies of dementia and environment have been of an experimental nature, whereby changes were introduced in the physical environment in order to measure outcomes (Day et al. 2000). Qualitative studies have focused on the physical environment as a socially constructed and dynamic agent and strategy to mitigate the worst effects of dementia (Morgan \& Stewart 1997, Messecar et al. 2002). But family caregivers' interests tend to be secondary foci in empirical research. Of the 71 studies Day et al. (2000) reviewed, only seven investigated outcomes concerning family members' well-being. A physical environment that enables care (as opposed to cure) and, therefore, regards caregivers' needs, appears to be considered only when professional, not lay, care is addressed.

Although family caregivers' expertise is acknowledged in matters relating to patients' environment, and professionals have used them to introduce changes in the home, caregivers' active role in creating and transforming this environment has received less attention. For 
instance, professionals seek family caregivers' opinions for improvements in residences (Grant \& Sommers 1998, Morgan \& Stewart 1999), and dementia guides for family care offer instructions to transform the home (e.g., Mace \& Rabins 1997), but their agency in transforming their material world tends to go unnoticed. An exception is the Messecar et al. (2002) study of family care of the elderly, in which caregivers were featured doing home improvements or moving to a new home when it no longer supported care. Albert's (1990) ethnographic study highlights family caregivers' efforts to modify the home for care. Pickards and Glendinning (2002) offered a quotation from a caregiver describing the device he had designed to clean the nasogastric tube of his relative suffering from Parkinson's disease.

In the area of dementia care, the crafts(wo)manship involved in building caring environments has been effaced by a focus on family caregivers as passive agents and secondary actors who are burdened by care, and in need of support and health care services (Manthorpe $e t$ al. 2003, Twigg 1989). But in the study reported here, family caregivers were primary agents and artisans and dementia care appeared as a kind of craft.

\section{THE STUDY}

\section{Methods}

The purpose of this grounded theory study was to identify strategies Colombian family caregivers used in the home to manage the demands of care of relatives in advanced stages of dementia. Advanced dementia was selected as it confronts caregivers with the greatest physical and emotional demands (Collins et al. 1993). In addition, caring for a relative with advanced dementia in the home is a rather frequent situation in Colombia, but one that is not well addressed in the research literature. Advanced dementia makes persons affected by it highly dependent on caregivers for their daily living. The care they need is constant and round the 
clock. These patients suffer significant cognitive and motor losses that prevent them from feeding themselves, dressing or washing (Maze \& Rabins 1997, Marks \& Sykes 2000). They are chair- or bed-bound, and cannot speak or recognize their relatives.

The study was conceived and data were collected by the first author in Medellín, Colombia. The Ethics of Research Committee of the University of Antioquia Faculty of Nursing granted human subjects approval. Data collection took place between September of 2000 and March of 2002. The University of Antioquia Neurosciences Research Group facilitated access to potential participants. A purposeful sampling strategy was initially employed to select long-time caregivers of relatives with advanced dementia who were completely dependent. Caregivers' sick relatives were diagnosed by Neurosciences' physicians using DSM- IV classification. Their dementia stage was established with the CDR test and their level of dependence with the Barthel scale for activities of daily living. Participants included 18 primary caregivers of relatives with advanced dementia: 15 women and 3 men, 10 of whom were between 51 and 75 years old, 5 of whom were between 25 and 50, and 3 of whom were less than 25 years old. Ten of the women caregivers were daughters; the remaining women were wives, sisters, or nieces. Among the three men were two sons and one husband. Seven of the participants had been caring for their relative 7-8 years; 9, 2-4 years; and 2 had assumed the primary caregiver role for less than one year. Eleven caregivers gave exclusive care or gave care for more than 60 hours per week, while seven gave care 20-60 hours per week. Nine of the relatives were suffering from Alzheimer's disease, four had vascular dementia, four had mixed dementia, and one relative had yet to receive a definite diagnosis of cognitive status. Sixteen of the relatives were completely dependent on their caregivers. 
As analysis proceeded, and information concerning what we eventually referred to as the material world of caregiving became a recurrent topic of conversation during interviews, a theoretical sampling strategy (Strauss \& Corbin 1998) was employed by which the interview data collected to date were reanalyzed, subsequent interviews were re-directed to elicit more information about the material world of the family caregivers, additional sources of information were sought, and more directed observations of caregivers' homes were conducted. In line with grounded theory procedures, data collection thus proceeded concurrently with analysis and ended when theoretical saturation was achieved (Strauss \& Corbin 1998). Altogether, 22 interviews were conducted with 18 caregivers, and 23 hours of participant observation occurred in 10 homes and 4 caregiver support groups.

Interviews with principal caregivers began with a grand tour question asking caregivers to describe a usual day in their lives, or a day they found significant in the care of their relative. Caregivers were also asked to describe caregiving activities, and how they managed acute crises in care. Later in the study, more questions were directed toward eliciting descriptions of changes in the home made to accommodate caregiving. Interviews lasted approximately 30-90 minutes, and all but one of them were conducted in caregivers' homes. Interviews were audiotaped and transcribed verbatim, except for three interviews that occurred during field work from which extensive notes were taken. An additional six interviews were conducted with two health care professionals working with dementia patients to collect data on their views of family caregiving. This type of data is referred to as "shadowed data" (Morse 2001); this data advances analysis by targeting relevant issues for theoretical sampling and thereby contributing to theoretical saturation. 
Constant comparison analysis (Glaser \& Strauss 1967, Strauss 1987) was used after entering data into QSR Nvivo. The first author - who is fluent in both Spanish and English translated data from Spanish to English. In order to maximize the trustworthiness of findings, they were discussed with participants and also, on three occasions, with groups of professional providers with expertise in the care of patients with dementia. Both the caregivers and providers responded well to the idea of caregivers making devices and arrangements in the home to enable care, and their feedback helped to refine analysis. In the presentation of results that follow, quotations have been edited and Spanish phrases inserted to improve the communication of participants' points of view. Pseudonyms are used to preserve their anonymity and confidentiality.

\section{FINDINGS}

Caring for a relative with dementia is a craft by which family caregivers transform the material world in which both caregiver and patient live (de la Cuesta 2003). Caregivers "built" (Handy et al. 2002) their environments by redesigning spaces, redistributing the human activities performed in these spaces, inventing new devices, and fashioning new uses for old devices to create a physical environment conducive to both caregiving and family life. This environment was built and rebuilt to accommodate the downward trajectory of dementia, to reduce the chaos attendant to the cognitive and motor decline characterizing advancing dementia, and to preserve social relations in the home. These family caregivers showed caregiving to be a craft and caregivers to be artisans.

At home in Medellín

From the caregiver's point of view, the home had to be spacious enough to accommodate a relative with dementia. As Esther observed about her mother: 
I will not move out of here with her, because it would be very difficult in an apartment or in a small house. Caring has to be in big spaces. This house is very big and I think this has also helped her to last so long.

Caregivers indicated that regular homes were not always able to accommodate relatives with dementia well. Accordingly, within the limitations of architecture and finances, caregivers transformed their homes. The traditional Medellín home is a one floor building, with large bedrooms of high ceilings opening to a central patio, corridors to the bathroom, and a kitchen situated at the far end of the house. These homes usually have a small front or back yard. This type of architecture was common up to the 1970's when apartments were built to a larger scale. Some modern homes retain characteristics of the traditional home, with a patio and spacious rooms. Although the majority of caregivers lived in apartments with little space, eight caregivers lived in homes with traditional features. Nevertheless all of them had to re-arrange something in the home to accommodate their sick relatives. An entry from field notes conveys this accommodation of space within the home:

The corridor ends in a patio where Ana (Gloria's sick sister) is. She is seated against the wall in a rocking chair that has stones on the legs to keep it still. The patio has bars on the ceiling and a cloth has been extended to provide shade for Ana. At the end of the patio, there is a washing machine and an ironing board. The walking space is free from objects. Everything is put against the wall to allow movement and circulation (Home visit with Gloria, 8 August 2001).

Pusimos la casa a su servicio: Accommodating the home to the patient From the moment they recognized the nature of dementia and the progressive deterioration associated with it, caregivers began the work of accommodating the home for the well-being and 
care of their relative with dementia. Caregivers began the process whereby the home was put to the service ("a su servicio") of the relative, but in a way that was safe for the caregiver. As Marta explained:

Soon after my husband became this way, I changed the floor in the bathroom, because it was very difficult to manage him. Once I almost fell on the tiles. So I put in a rough floor. And other little details like this in the home. . . to be more at his service than at ours. I put the gas in the kitchen stove because he was moving all the stove plugs. He moved everything. With gas, there is a handle that moves to zero. He did not realize this and, therefore, could not open it. The same with the water keys. I closed them out there, where the water authorities installed the keys to the water that comes to this place. I put two keys to be able to close the water, because when I left the home, he used to come and open one key or the other, and a lot of things like this. Yet family caregivers were careful not to change things so much that the home would become completely strange and, thus, frightening for the relative. In the same way dementia patients became strangers to the family (Muñoz et al. 1999 ), so the environment could become strange to the patient. A patient might be frightened of the bathroom mirror or of the appearance of the floor and, therefore, resist care. Silvia explained that one day, she placed a big fruit on the dinner table. Because her mother thought it was a child drowning, she could not put anything on the table anymore. Describing a change of bedrooms, Veronica described the need to ensure that changes made to the home would preserve the ill person's well-being. As she recalled:

My mother slept in this room and we said to her: "Amparo, go to the bedroom to put on your pyjamas." But she did not go to the room where she was sleeping, but to the other one where she used to sleep. She sort of knew: "This is my bedroom." She has 
slept there all her life and when we changed it, she knew that this was really her bedroom. . .My brother would like very much to move the bathroom to the patio, but he is hesitant because my mother knows now where the bathroom is.

Caregivers redesigned their living spaces either by changing them physically or by changing the human activity occurring in these spaces. Caregivers reformed their homes inside e.g., the bathroom - and outside, e.g., by putting fences around the home. Caregivers also relocated their sick relatives, in the case of recurrent and room-based activities, such as eating and sleeping, as when Gloria changed her sister's bedroom to be close to the bathroom. Caregivers also allowed room-based activities to be performed anywhere in the house. Ramón followed his father around the house to give him his food. All of these changes were made to facilitate care or surveillance. In some cases, the person with dementia was moved and, in others, the caregiver moved with the patient. Adela and her husband moved their bedroom to be close to her mother so they could hear her at night if she needed help. Other caregivers, like Veronica, slept in the same room as the relative.

Spaces were transformed both by physically altering the spaces themselves and by virtue of the human activities occurring in those spaces, or what urban planners call changes in "land use" (Handy et al. 2002). Balconies, terraces, and patios become solariums where relatives could stay warm after the bath, take a nap, or just "get the sun," as Olga commented. Corridors were used as promenades where relatives were taken for "a walk." Rooms become places for the relative to "visit," as family caregivers took patients on "tours" of their own homes and thereby transformed them into exciting places of discovery and adventure.

Home spaces took on new functions and, therefore, new appearances. When Julian's father broke his hip and was confined to bed for a few months, his bedroom took on the 
appearance of a hospital room. In Gloria's home, what was previously a patio to do the laundry was transformed into a resting place for her sick sister where she could sit in the sun. In Julian's home, the corridor was used to wash the person. The patio was also used as a bathroom to bathe the relative. Lucero described this new use of the patio:

We do not take her to the bathroom to have her bath, but bathe her here in the patio. We do not have a shower, but a little hose and we bathe her here, outside. We do not bath her inside, where we all have our baths, but here where there is a toilet close by. So we avoid the risk of hurting her trying to get her into where the regular bathroom is.

Although some changes were undertaken to facilitate patient care, others were directed toward making the home a safe place for the relative with dementia. Family caregivers appreciated the risks that an unmodified house posed for these family members, who could simply leave the home and suffer serious accidents in the home, among them, becoming trapped in the most amazing ways and in the most unforeseen places. One day Camilo had to leave his wife Jacinta on her own at home. When he returned, he found Jacinta on her knees, with her head trapped in the bars of her bed, and visibly exhausted from trying to escape. Caregivers who had to leave their relatives alone, either at night or during the day, had to improvise to ensure a safe environment for them. Lucero placed an extra bed close to her sister's bed in case she fell during the night. Silvia observed:

I had to leave my mother here: seated, tied up, and out of reach of everything, because she knocks down everything. To leave her, I had to pull away her chair so she could not reach this, or get anything over there. 
Me lo tuve que inventar: Fashioning caregiving tools

The family caregivers needed tools to do their work. Because they could not afford to buy them or because they were not available, they had to make these tools themselves or reinvent existing objects, like true artisans. In the hands of these caregivers, everyday objects became technological objects in the domain of caregiving (Sandelowski 2000). Caregivers modified beds to make them more similar to hospital beds, i.e., raising them to facilitate caregiving and attaching rail-like devices to prevent relatives from falling out of bed. Caregivers transformed plastic chairs into wheel chairs by building platforms with wheels and attaching devices to prevent their relatives from falling over or out of these chairs. Caregivers used syringes to give fluids and baby alarms to monitor relative's sleep. They made their own straight jackets to restrain harmful patient movements, and used plastic soda bottles to clean nasogastric tubes. As Tulia recalled:

At the beginning, my sister ate normally with a spoon. But then she began to deteriorate and started closing her lips. So we invented this... a regular bottle with a kind of teat, making it into a feeding bottle to get past her closed mouth.

The use of devices originally intended for one function to serve other functions suggests family caregivers' "enlightened consciousness," or, as Lucero put it, " se le iluminó la conciencia," to refer to her niece's (with whom Lucero shares caregiving) recognition of the possibilities in the devices she already possessed to solve a caregiving problem. Mari's description of how she used her son's bicycle to rehabilitate her mother from a stroke exemplifies the ingenuity of these caregivers. As Mari explained:

They told me that after the third stroke that my mother would not be able to walk again. So I took the my son's bicycle, which is small, and put it upside down. I tied 
her sick foot to the pedal and pushed with the other pedal. Her foot stayed this way (she makes a circular movement with her hands) and I tell her to "go on, go on, and go on, go on, and go on.” My mother achieved strength in her leg. I also added a bag with two or three little stones. As my mother gained more strength, I put more sand, and more sand, and more sand. I made two weights of sand for my mother.

Family caregivers transformed the objects of everyday life, not only when they materially refashioned them, but also when they related to them in new ways. As Mari's ingenuity indicated, objects are not fixed entities, but rather participants in and products of social life (Blumer 1969). Olga filled the drip plastic bottles used in dialysis with water to make a water mattress to prevent pressure sores. The meaning of objects resided not in the object itself, but rather was produced in interaction with them. Moreover, caregivers both designed and tested their inventions. Via trial and error, Cecilia determined that a device intended for a child with hydrocephalus could be useful for an incontinent relative.

Ahí, hay una persona: Using devices to preserve identities and relations

Caregivers also used devices to create moments of togetherness, such as using the Bible to read to relatives, and to help relatives feel involved and useful. Mercedes recalled: When I was going to sew, I brought my mother along, put music on, and seated her by me. As I was sewing, I said to her "come, help me dear, I am having difficulties with this dress." She laughed, took the material, and played with it. I pretended that we were sewing together. . I am also able to keep an eye on her.

Objects served to help sick relatives preserve their own identity and to remind others that there was, in Mercedes' words, a "human being in there" ("ahí, hay una persona"), under the façade of dementia. For instance, Tulia commented that her mother had her own spoon, chairs, bed linens, 
and towels. Mercedes' mother had her own "mercado" (1-2 weeks supply of food) that everyone at home knew and cared for, and Veronica safeguarded her mother's favorite chair. Personal belongings were protected and kept apart to give the relative a special status. As Tulia put it: My mother has a lot of privileges ("privilegios")... Here no one takes anything that is hers, she has everything that is hers, and everyone here respects that, everyone knows it.

By surrounding their loved ones with their personal possessions and by saving their favorite objects for their exclusive use, family caregivers reinforced their personhood. Personal belongings were an extension of affected relatives that caregivers used to preserve their connection with them. Devices served as mementos of who the loved one was before the onset of severe dementia. Berta worked to maintain this connection via objects. As she recalled: I said "No daddy, this is your room." He replied "no it is not my room." Then I said "come with me to see, where is your pyjama? Let us go and look for the pyjama." So he goes to the room and we search and he realizes it is his room. When he does not let me guide him, I take out of the room his bathroom sleepers and his clothing for him to see that they are really his.

Caregivers created devices to remind them that their relative was "alive". For instance, in Mercedes' home, they put up a board where the family wrote each word that the relative said. These devices allowed caregivers to treat the relative as a fully functioning person, despite their severe mental deterioration. In essence, the caregivers used objects to avoid treating relatives like objects. These uses of objects reflect the "instrumental role material artifacts play in the construction (and preservation) of personhood" and social relations (Layne 2000, p. 338). 
Claro que cambiamos cosas: The costs of rebuilding the environment

Family caregivers sought to create built environments where affected family members could live comfortably with the greatest possible quality of life. They created hybrid places, or almost-homes (Albert 1990), to accommodate the changing trajectory of dementia and to transform the home into a place where all family members could live safely and, at the same time, care for their sick relative. But this transformation was costly, not financially, but rather because the home slowly lost its home-like character acquiring the appearance of an institution (Goffman 1992). Spaces were locked, ornaments and furniture were removed, and rooms were refashioned. As Mercedes observed:

I had to put away ornaments and pocket knifes - sharp things - and other things. We had to give away many things as we did not know what she could get hold of. Caregiving activities, such as the constant surveillance of the ill family member, reinforced the institutional feeling of the home. Transformed to provide custodial and terminal care, the home was no longer as inviting to others. Both patients and their families became secluded, as the home was no longer designed to entertain visitors. When asked if people came to visit, Tulia answered: "no. Visitors (visitas) are not really coming; few people outside the home come here to visit." And most visits were organized around the sick relative, as visitors came to help with care. Now populated with bed pans, water mattresses, wound dressings, wheel chairs, hospital beds, urinary and nasogastric tubes, and the makeshift items caregivers fashioned to care for their relatives, the home became increasingly medicalized. Paradoxically, these caregivers transformed their homes to be more hospital-like, while hospitals and other institutions of care (e.g., birthing rooms, 
hospital playrooms, nursing homes) have been transformed to appear more home-like (Day et al. 2000).

Yet offsetting the medicalized appearance of the home were the religious objects introduced into the home, such as religious images, small altars with offerings, holy books, rosaries, and portraits of local saints, e.g., Marianito, believed to work miracles especially for persons with dementia. These objects accentuated the hybridization of the home. With the creation of this hybrid place, where family life is combined with clinic life, the affected relative is both a family member and a patient, an adult and a helpless baby. Caregivers, in turn, are spouses or children, and nurses and mothers. Identities merged in the hybrid home. The importance that places have on identities has been documented in the literature. The spaces in which caregivers lived with their relatives were not neutral locations (Agier 2002), but rather places where "identities crystallized" (Holloway \& Valentine 2000, p. 770). When the relative died or the death was anticipated, families considered moving out. As Esther observed shortly after her aunt died, "the home feels alone." The built environment is empty of purpose. DISCUSSION AND CONCLUSION

The importance of the physical environment as the "silent partner" (Noell 1995) in caregiving has been well-documented (Grant \& Sommers 1998, Morgan \& Stewart 1997, Stichler, 2001). The home has become the preferred place of care for relatives with dementia in Europe (Marks \& Sykes 2000) and the United States (Czaja et al. 2000). The few studies conducted in this area indicate that this is also the case in Latin America (e.g., de la Cuesta 2001).

Family caregivers' creative capacities in designing devices and systems of care have not necessarily been featured in studies of either caregiving or the place of care, but this study shows 
them to exist. The findings of this study emphasize the importance of the material world as a window into lived experience (Sandelowski 2003), and the critical role caregivers assume as bricoleurs who are able to see the possibilities of spaces and everyday objects, and to use them in ingenious ways. Interpreting the concept originally introduced in 1966 by Levi-Strauss in The savage mind, Crotty (1998 p. 50) described the bricoleur as a:

makeshift artisan ... who makes something new out of a range of materials that had previously made up something different ... Bricoleurs are utterly focused on what they have to work with, (on) what can be made of these items, (on) what they lend themselves to becoming.

Caring for relatives at home is a family value in Latin culture (Czaja et al. 2000, SanchezAyéndez 1993). The caregivers in this study showed this value as they strived to care for their relatives to the end, "hasta lo ultimo" (de la Cuesta, 2003). Their homes thus became the natural places for terminal care. Yet as the home becomes a hybrid place for both family life and caregiving, it can also become a place of burden rather than respite from the everyday burdens of life. In countries like Colombia of scarce resources for family care (Isla Pera 2000, Klaasen et al. 1988), where specialized equipment to care for dependent patients is limited, not covered by health insurance, and therefore out of reach of many families, having to build this equipment adds to the burden of caregiving even as it fulfills the imperative to care. In other national contexts, where stronger social and health care systems exist, family caregivers' may not be required to carry so much of the burden of creating physical environments amenable to caregiving in the home. Further research in this area could contribute to a better understanding of the burden of caregiving engendered by the need to rebuild the home as an environment of care. 
Health care professionals' appreciation of family caregivers' craft can lead to a new regard for them as creating health resources. Community nurses can pass on to other families what they learn from family caregivers concerning home improvements, the development of devices, and the therapeutic use of everyday objects. Nurses have themselves a long history of material innovation and improvisation (Sandelowski 2000). Health care practitioners' awareness of the importance of the material world of family caregiving will assist them to assess caregivers' needs, and support them in their building efforts, especially those who lack the inventiveness of the caregivers featured in this report. But this should never substitute for nurses' continued activism to ensure national health resources that will make it less necessary for so much of the burden of caregiving to fall on families.

In conclusion, the findings of the study reported here show the value of material culture and "place-sensitive" (Andrews 2002) approaches to the study of caregiving. Health researchers are increasingly recognizing the importance of the material and the physical as key aspects of the lived experience of both caregiving and family life. The findings emphasize family caregivers' capacities to build caring environments and to engage in activities akin to architects, designers, and urban planners; the contribution of the material environment to the social environment of care; and the home environment as a hybrid place where both caregivers and the loved ones they care for are themselves transformed. 


\section{REFERENCES}

Agier M. (2002) Between war and city-towards an urban anthropology of refugee camps. Ethnography 3, 317-341

Albert S. M. (1990) The dependent elderly, home health care, and strategies of household adaptation. In: The home care experience (Gubrium J.F. and Sanker A. Eds). SAGE, Newbury Park, California, USA, pp 19-36.

Andrews G. J. (2002) Towards a more place-sensitive nursing research: An invitation to medical and health geography. Nursing Inquiry 9, 221-238.

Blumer H. (1969) Symbolic Interactionism. Prentice-Hall, Englewood Cliffs, New Jersey, USA.

Czaja S. J., Eisdorfer C. \& Schulz R., (2000) Future Directions in Caregiving: Implications for Intervention Research. In: Handbook of Dementia Caregiving, Evidence-based interventions, (Schulz R. Ed), Springer, New York, pp. 283-319.

Cohen-Mansfield J. \& Werner P. (1998) The effects of an enhanced environment on nursing home residents who pace. The Gerontologist 38, 199-208

Collins C., Liken M., King S. \& Kokinakis C. (1993) Loss and Grief Among Family Caregivers of Relatives With Dementia. Qualitative Health Research 3, 236-253.

Crotty M. (1998). The foundations of social research: Meaning and perspective in the research process. SAGE, London.

Day K Carreon D., \& Stump C. (2000) The therapeutic design of environments for people with dementia: A review of the empirical research. The gerontologist 40, 397-416 de la Cuesta C. (2001) Review of the Latin American literature on research in family care of patients with dementia. Unpublished Review Report- Pacific-Rim Grant. Faculty of Nursing. Universidad de Antioquia. Medellín. Colombia. 
de la Cuesta C. (2003) Cuidado artesanal: un estudio cualitativo sobre cuidado familiar de pacientes con demencia avanzada. Unpublished research report. Faculty of Nursing. Universidad de Antioquia. Medellín. Colombia.

Glaser B. \& Strauss A. (1967) The discovery of grounded theory: strategies for qualitative research. Aldine, New York.

Gesler W. (1992). Therapeutic landscapes: Medical issues in the light of the new cultural geography. Social Science \& Medicine, 34, 735-746.

Grant L.A. \& Sommers A.R. (1998) Adapting living environments for persons with Alzheimer's disease. Geriatrics 53, 61-S65

Goffman E. (1992) Internados. Amorrortu, Buenos Aires, Argentina.

Halloway S. L. \& Valentine G. (2000) Spatiality and the New Social Studies of Childhood. Sociology 34, 763-783.

Handy S.L., Boarnet M.G., Ewing R. \& Killingsworth R. E. (2002) How the built environment affects physical activity - Views from urban planning Am J Prev Med 23, 64-73.

Isla Pera P. (2000) El cuidador familiar. Una revisión sobre la necesidad del cuidado doméstico y sus repercusiones en la familia. Cultura de los Cuidados 4, 187-194.

Klaasen G., Quiroga P., Zavala M., Castro M. \& Vidal. D. (1988) Redes de apoyo medico-social para pacientes con demencia. Comunas de Concepción y Quillón, 1996. Cuadernos Médicos Sociales 39,111-115.

Krieger J. \& Higgins D.L. (2002) Housing and health: time again for public health action. American Journal of Public Health, 92, 758-768

Layne L. L. (2000) "He was a real baby with baby things": A material culture analysis of personhood, parenthood and pregnancy loss. Journal of Material Culture, 5, 321-345. 
Mace N. L. \& Rabins P.V. (1997) Cuando el día tiene 36 horas. 2nd Spanish edition. Pax México, México DF, México.

Manthorpe M.A., Lliffe S. \& Eden A. (2003) Testing Twigg and Atkin's typology of caring: a study of primary care professionals' perceptions of dementia care using a modified focus group method. Health and Social Care in the Community 11, 477-485.

Marks D.F. \& Sykes M. (2000) Dealing with dementia: recent European research. Middlesex University Press, London.

Messecar D.C., Archbold P.G., Stewart B.J. \& Kirschling J. (2002) Home Environmental Modification Strategies Used by Caregivers of Elders. Research in Nursing and Health 25, 357-370

Morgan D.G. \& Stewart N.J. ( 1997) The Importance of the Social Environment in Dementia Care. Western Journal of Nursing Research 19, 740-761

Morse J. (2001) Editorial: Using Shadowed Data. Qualitative Health Research 11, 291-292.

Morgan D.G. \& Stewart N.J. (1999) The Physical Environment of Special Care Units: Needs of Residents With Dementia From the Perspectives of Staff and Family Caregivers. Qualitative Health Research 9,105-118.

Muñoz González L.A., Arancibia Silva P. \& Paredes Arévalo L.P. (1999) La experiencia de familiares cuidadores de pacientes que sufren Alzheimer y competencias del profesional de enfermería. Investigación y Educación en Enfermería 17, 35-50.

Noell E. (1995) Design in nursing homes: Environment as a silent partner in caregiving. Generations: The journal of the Western Gerontological Society 19, 14-19.

Nightingale F. (1859/1992) Notes on Nursing: What It Is and What It Is Not. Commemorative Edition of 1859. Lippincott, Philadelphia, USA. 
Pickard S. \& Glendinning C. (2002) Comparing the role of family carers and nurses in the domestic health care of frail older people. Health and Social Care in the Community 10, $144-150$

Sánchez Ayéndez M. (1993) La mujer como proveedora principal de apoyo a los ancianos: el caso de Puerto Rico. In Género, Mujer y Salud (Gómez, Gómez E. Ed.) Organización Panamericana de la Salud-OMS, Washington, pp.286-291

Sandelowski M. (2000) Devices and desires: Gender, technology, and American nursing. University of North Carolina Press, Chapel Hill, North Carolina, USA.

Sandelowski M. (2003) Taking things seriously: Studying the material culture of nursing. In Advanced qualitative research for nursing (Latimer J. Ed.), Blackwell Science, Oxford, UK, pp. 185-210.

Stichler J.F. (2001) Creating healing environments in critical care units. Critical Care Quarterly 24, 1-20

Strauss A. (1987) Qualitative Analysis for Social Scientists. Cambridge University Press, Cambridge.

Strauss A. \& Corbin J.M. (1998) Basics of Qualitative Research. SAGE, Thousand Oaks, California, USA.

Twigg J. (1989) Models of carers: How do social care agencies conceptualise their relationship with informal careers? Journal of Social Policy 18, 53-66 